\title{
Extending Barrett's esophagus cancer risk profile towards genetic abnormalities
}

\author{
Reza Asari, Martin Riegler and Sebastian F Schoppmann
}

\section{Dear Editor,}

With interest we read the article by Bajpai et al. [1], entitled "Prolonged exposure to acid and bile induces chromosome abnormalities that precede malignant transformation of benign Barrett's epithelium", which has been published in the recent issue of Molecular Cytogenetics. Barrett's esophagus results from gastroesophageal reflux and harbors an increased risk for the development of esophageal adenocarcinoma ( $0.5 \%$ annual cancer risk) $[2,3]$. Using a fascinating in vitro approach the authors modeled the effect of gastroesophageal reflux on immortalized Barrett's esophagus cells [1]. Bajpai et al. found that intermittent exposure of BAR-T cells to acid and bile for 18 to 78 weeks caused a spectrum of genetic abnormalities typical for cancer development, including polyploidy, loss of chromosomes and the development of transformed clones. In addition, the genetic changes evoked by acid and bile exposure format the target protein receptors for tumor stimulating growth factors, i.e. epidermal growth factor (EGF), which are known to promote the growth of gastrointestinal cancers [4]. In contrast, unexposed cells did not exhibit these abnormalities. Remains to be questioned, if the striking observations made by the authors may be of clinical relevance for the diagnosis and the therapy of Barrett's esophagus?

Conceptually, Barrett's esophagus results as the consequence of a complex neurohumoral response of the esophageal mucosa to gastroesophageal reflux including acid and bile [2,3]. Thus, by theory, the removal of Barrett's tissue and the elimination of reflux should contribute to cancer prevention. Going in line with with this notion, recent studies found that elimination of reflux by effective antireflux surgery contributes to increase the yield of radiofrequency ablation to eradicate Barrett's esophagus, when compared to ablation and postablational proton pump inhibitor (PPI) therapy, which

\footnotetext{
* Correspondence: reza.asari@meduniwien.ac.at

University Clinic of Surgery, Medical University Vienna, Vienna General Hospital, Waehringer Guertel 18-20, Vienna, Austria
}

solely changes the $\mathrm{pH}$ of the reflux, but not the reflux per se [3,5].

Given that the genetic abnormalities assessed by Bajpai et al. [1] can be visualized by modern endoscopic in vivo staining techniques, this may enable us to detect tissue at risk for cancer development $[4,6,7]$ and specifically target our therapies (i.e. ablation, endoscopic resection) towards these areas [3]. Therefore a risk profile- (anamnestic, demographic \& endoscopic, esophageal function tests characteristics) [3] and endoscopically visualized genetic profile- based tailored management of Barrett's esophagus for cancer prevention may be realistic in the future $[1,4,6,7]$. Thus, Barrett's positive individuals with increased reflux due to severely impaired function of the esophagus may be offered elimination of acid and bile reflux by an effective anti reflux surgery prior to ablation [3,5]. In contrast, ablation and subsequent PPI therapy seems reasonable for those with Barrett's esophagus and normal esophageal function and reflux monitoring [3]. Endoscopic radiofrequency ablation would then be targeted to in vivo staining positive genetic abnormal areas $[1,6,7]$. Taken together, time seems ready to design prospective clinical trials to assess the impact of the above mentioned biological markers for cancer prevention. The authors are kindly asked to comment on the above considerations.

Sincerely,

Reza Asari, Martin Riegler, Sebastian F. Schoppmann.

Received: 28 December 2012 Accepted: 11 January 2013

Published: 4 March 2013

\footnotetext{
References

1. Bajpai M, Aviv H, Das KM: Prolonged exposure to acid and bile induces chromosome abnormalities that precede malignant transformation of benign Barrett's epithelium. Mol Cytogen 2012, 5:43. ahead of print.

2. Mesteri I, Lenglinger J, Beller L, Fischer-See S, Schoppmann SF, Wrba F, Riegler M, Zacherl J: Assessment of columnar-lined esophagus in controls and patients with gastroesophageal reflux disease with and without proton-pump inhibitor therapy. Eur Surg 2012, 44:304-313.

3. Mesteri I, Beller S, Fischer-See S, Schoppmann SF, Lenglinger J, Wrba F, Rlegler M, Zacherl J: Radiofrequency ablation of Barrett's esophagus and early cancer within the background of the pathophysiology of the disease. Eur Surg 2012, 6:366-382.
} 
4. Wang YK, Gao CF, Yun T, Chen Z, Zhang XW, Lv XX, Meng NL, Zhao WZ: Assessment of ERB2 and EGFR gene amplification and protein expression in gastric carcinoma by immunohistochemistry and fluoresence in situ hybridization. Mol Cytogen 2011, 4:14. doi:10.1186/17558166-4-14.

5. Siddiqui MRS, Abdulaai Y, Ali H, Hasan F: A meta-analysis of outcomes after open and laparoscopic nissen's fundoplication in the treatment for gastro-Oesophageal reflux disease. Eur Surg 2011, 44(3):138-149.

6. Graphodatsky AS, Trifonov VA, Stanyon R: The genome diversity and karyotype evolution of mammals. Mol Cytogen 2011, 4:22. doi:10.1186/ 1755-8166-4-22

7. Maric I, Viaggi S, Caria P, Frau DV, Degan P, Vanni R: Centrosomal and mitotic abnormalities in cell lines derived from papillary thyroid cancer harboring specific gene alterations. Mol Cytogen 2011, 4:26. doi:10.1186/ 1755-8166-4-26

doi:10.1186/1755-8166-6-10

Cite this article as: Asari et al.: Extending Barrett's esophagus cancer risk profile towards genetic abnormalities. Molecular Cytogenetics 2013 6:10.

\section{Submit your next manuscript to BioMed Central and take full advantage of:}

- Convenient online submission

- Thorough peer review

- No space constraints or color figure charges

- Immediate publication on acceptance

- Inclusion in PubMed, CAS, Scopus and Google Scholar

- Research which is freely available for redistribution 